
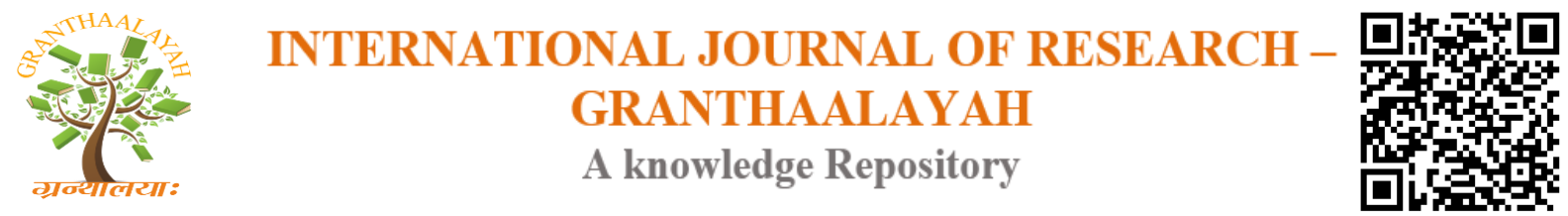

Social

\title{
INDEPENDENT AND CONJOINED EFFECT OF TYPES OF HOSPITALS AND EDUCATIONAL QUALIFICATION ON JOB SATISFACTION OF NURSES IN M.P.
}

\author{
Anjali Pandey ${ }^{* 1}$, Dr (Smt) Smita Jain ${ }^{2}$ \\ ${ }^{*} 1$ Research Scholar, RDVV Jabalpur, INDIA \\ ${ }^{2}$ Professor and HOD, Department of Psychology Govt P.G College, Narsinghpur, INDIA
}

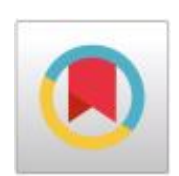

DOI: https://doi.org/10.29121/granthaalayah.v4.i9.2016.2536

\section{ABSTRACT}

The aim of the present study was to find out the impact of types of hospital on Job Satisfaction of nurses. For this a sample of 300 Nurses with diploma or degree as Educational qualification of Government and Private Hospital was randomly selected. Job satisfaction scale by Dr. Amar Singh and Dr. T.R. Sharma was used. It was found that there was impact of type of hospital on Job satisfaction. Those working in Government hospital were more satisfied than those working in Private hospital. Educational qualification had no role to play in Job satisfaction.

Keywords:

Nurses, Hospital, Job Satisfaction, Education Qualification.

Cite This Article: Anjali Pandey, and Dr (Smt) Smita Jain, "INDEPENDENT AND CONJOINED EFFECT OF TYPES OF HOSPITALS AND EDUCATIONAL QUALIFICATION ON JOB SATISFACTION OF NURSES IN M.P." International Journal of Research - Granthaalayah, Vol. 4, No. 9 (2016): 63-67.

\section{INTRODUCTION}

For proper and speedy recovery of patients it is very important to have very good nursing services in addition to proper medical treatment. Job satisfaction reflects an employee overall assessment of their job, particularly their emotions, behavior, and attitudes about their work experience. It is one of the most heavily researched topics in Industrial-organization psychology with several thousand published studies. Job satisfaction has theoretical and practical utility for the field of psychology and has been linked to important job outcomes including attitudinal variables, absenteeism, employee turnover, and job performance. Job satisfaction is strongly correlated with attitudinal variables such as job involvement, organizational commitment, job tension, frustration and feeling of anxiety etc. 
This research was undertaken to find out whether there was any impact of nature of organization (Government and Private) on job satisfaction of nurses in relation to considered the Educational qualifications of nurses.

\section{OBJECTIVE}

To study the influence of types of Hospital, educational qualification and their interaction on job satisfaction of nurses.

\section{HYPOTHESIS}

There is no significant influence of Types of Hospital, Educational Qualification and their interaction on Job Satisfaction of Nurses.

\section{SAMPLE}

A sample of 150 Nurses each was selected randomly from government and private hospitals. They were stratified on the basis of Educational Qualification in Diploma and Degree holders.

TEST- Job Satisfactions Scale by Dr. Amar Singh And Dr.T.R.Sharma.

\section{METHOD}

Through random sampling four hospitals were selected (two government and two private hospitals). The nurses of the selected hospitals were adminstered upon a structured questionnaire on Job Satisfaction by Dr. Amar Singh and Dr. T.R. Sharma by the researcher. The scoring was done and the score were analysed.

\section{ANALYSIS ${ }^{2}$ AND DISCUSSION OF RESULTS}

The objective was to study the influence of Types of Hospital, Educational Qualification and their interaction on Job Satisfaction of Nurses. There were two Types of Hospital, namely, Government and Private. Diploma in Nursing and Graduation in Nursing were the two levels of Educational Qualification of Nurses. Thus the data were analyzed with the help of 2X2Factorial Design ANOVA.

Table 1: Educational Qualification Wise N, Mean, SD of Job Satisfaction of Nurses

\begin{tabular}{|l|l|l|l|}
\hline TYPES OF HOSPITAL & N & Mean & SD \\
\hline GOVERNMENT HOSPITAL & 150 & 70.25 & 12.57 \\
\hline PRIVATE HOSPITAL & 150 & 60.86 & 8.08 \\
\hline
\end{tabular}

Table 2: Summary of 2 x 2 Factorial Design ANOVA of Job Satisfaction of Nurses

\begin{tabular}{|l|l|l|l|l|}
\hline Source of Variance & df & SS & MSS & F-value \\
\hline Types of Hospital (A) & 1 & 5075.39 & 5075.39 & $45.20^{* *}$ \\
\hline Educational Qualification (B) & 1 & 18.11 & 18.11 & 0.16 \\
\hline A X B & 1 & 31.30 & 31.30 & 0.28 \\
\hline
\end{tabular}




\begin{tabular}{|l|l|l|l|l|}
\hline Error & 296 & 33234.59 & 112.28 & \\
\hline Total & 299 & & & \\
\hline
\end{tabular}

**Significant at 0.01 level

From Table 1, it is evident that the F-value for Types of Hospitals is 45.20 which is significant at 0.01 with $\mathrm{df}=1 / 296$. It shows that the mean scores of Job Satisfaction of Nurses working in Government Hospitals and Private Hospitals differ significantly. So there was a significant influence of Types of Hospitals on Job Satisfaction on Nurses. Thus the null Hypothesis that there is no significant influence of Types of Hospitals on Job Satisfaction of Nurses is rejected. Further, Government Hospital $(\underline{\mathrm{M}}=70.25)$ and Private Hospital $(\underline{\mathrm{M}}=60.86) \mathrm{F}$ at $(1,296)=$ 45.20, $\mathrm{P}<0.01$. Job satisfaction among nurses in Government hospital is greater than for Private hospital. It may, therefore, be said that Job Satisfaction of Nurses working in Government Hospitals was found to be higher than those working in private Hospitals.

From Table 1, it can be seen that the F-value for Educational Qualification is 0.16 which is not significant. It shows that the mean scores of Job Satisfaction of Nurses having Graduate in Nursing and Diploma in Nursing Qualification did not differ significantly. So, there was no significant influence of Educational Qualification on Job Satisfaction of Nurses. Thus, the null Hypothesis, that there is no significant influence of Educational Qualification on Job Satisfaction of Nurses, is not rejected. It may, therefore, be said that Job Satisfaction was found to be independent of Educational Qualification of Nurses.

From Table 1, it can be seen that the F-value for the interaction between Types of Hospital and Educational qualification is 0.28 which is not significant. It shows that the mean scores of Job Satisfaction of Nurses working in Government and Private Hospitals having different Educational Qualification did not differ significantly. So there was no significant influence of interaction between Types of Hospital and Educational Qualification on Job Satisfaction of Nurses. Thus, the null Hypothesis that there is no significant influence of interaction between Types of Hospital and Educational Qualification on Job Satisfaction of Nurses is not rejected. It may, therefore, be said that Job Satisfaction of Nurses was found to be independent of interaction between Types of Hospital and Educational Qualification of Nurses.

Job Satisfaction of Nurses working on Government Hospitals was found to higher than those working in private Hospitals. From the results presented in the this research it is clear that there is significant influence of types of hospital on Job Satisfaction whereas there is no significant influence of Educational qualification on Job Satisfaction. The Government hospital nurses are better in comparision to Private hospital nurses. This is obvious since there is greater security of job alongwith conditions of service. In a private hospital at times there is insecurity as for as the continuation is concered. The routine is more rigid and since most of the patients belong to at least average socio-economic status, they are more aware about the duties in a private hospital. Being educated they expect more sincere duties from the staff and as such the nurses are in some what stress. Along with this there are other differences like the nurses in the Government Hospital work in shift and have greater facilities as far as leave and other benefits are concerned. Even financially the government hospital nurses are better than those working in private hospitals, which in turn influences their Job satisfaction. This finding is supported by (Jahan, T. \&Kiran, U.V. $(2013)^{3}$ and Patil, Saroj B. and Choudhari, P.T. (2011) ${ }^{7}$. Who found that the 
Job Satisfaction of Nurses working in Government Hospitals was found to be higher than those working in Private Hospital. This finding is contradicted by (CHARLOTTE PIETERSEN $(2005)^{1}$, Mrayyan, Majd Tawfeeq (2005) ${ }^{5}$ and Taranjit Kaur Rao1 Ms. Shiva Malik2 (2012) ${ }^{8}$ who found that the Job Satisfaction of Nurses working in Government Hospitals was found to be lower than those working in Private Hospital. The reason for this contradiction could be because the fact that some private hospitals are at times better managed, more prestigious and more paying than the Government hospitals. Laschinger, et al (2016) ${ }^{4}$ found that the Overall, new graduate nurses were positive about their experiences and committed to nursing. However, over half of new nurses in the first year of practice reported high levels of Emotional exhaustion and many witnessed or experienced incivility $(24-42 \%)$ at work. These findings showed that working conditions for new graduate nurses were generally positive and stable over time, although workplace mistreatment was an issue to be addressed.

Job Satisfaction of Nurses was found to be independent of interaction between Types of Hospital and Educational Qualification of Nurses. This can be explained by the fact that neither type of hospital nor educational qualification had any effect on job satisfaction of nurses, hence their interaction also has nill effect on job satisfaction.

From the above results the hypothesis related to types of hospital and Job satisfaction is not accepted whereas the one related to Educational qualification and Job satisfaction is not rejected.

\section{CONCLUSION}

1) There is significant influence of types of Hospitals on Job Satisfaction of Nurses. The Government Hospital nurses have greater Job Satisfaction than those working in Private Hospital.

2) There is no significant influence of Educational qualification on Job Satisfaction of Nurses.

3) There is no significant influence of Types of Hospital, Educational Qualification and their interaction on Job Satisfaction of Nurses.

\section{REFERENCES}

[1] CHARLOTTE PIETERSEN 2005 job satisfaction of nursing staff $(N=109)$ at a government hospital. charlottep@ul.ac.za Department of Human Resource Management University of Limpopo SA Journal of Human Resource Management, 2005, 3 (2), 19-25 SA Tydskrif vir Menslikehulpbronbestuur, 2005, 3 (2), 19-25.

[2] Garret, H. E., \& Wood worth, R. S. (1966). Statistic in Psychology and Education. 6th Edition. Ninth Indian Reprint). Bombay. India: Vakils, Feffer and Simons.

[3] Jahan, Tarannum \& Kiran, U.V.(2013) An evaluation of Job Satisfaction of Nurses across working sectors. International Journal of Humanities and Social Science Invention. 2013 Vol.2(6).

[4] Laschinger, Heather K. Spence; Cummings, Greta; Leiter, Michael; Wong, Carol; MacPhee, Maura; Ritchie, Judith; Wolff, Angela; Regan, Sandra; Rhéaume-Brüning, Ann; Jeffs, Lianne; Young-Ritchie, Carol; Grinspun, Doris; Gurnham, Mary Ellen; Foster, Barbara; Huckstep, Sherri; Ruffolo, Maurio; Shamian, Judith; Burkoski, 
Vanessa; Wood, Kevin; Read, Emily(2016). Conducted a time-lagged study of new graduate nurses' transition to practice. International Journal of Nursing Studies.May2016, Vol. 57, p82-95. 14p.

[5] Mrayyan, Majd Tawfeeq.(2005) Job-Satisfaction and Retention by comparing Public and Private Hospitals in Jordan. Journal of Nursing Management. Jan2005, Vol. 13 Issue 1, p40-50. $11 p$.

[6] Negi Ankur. (2013). Industrial Psychology. First Edition CBS Publishers \& Distributors Pvt Ltd. ISBN: 978-81-239-2290-4.Printed at India Binding House Noida. p.92.

[7] Patil, Saroj B. \&Choudhari, P.T. (2011) Assessment of Job Satisfaction and H R Practices: A case study of Nursing Staff. AJRSH, Volume 1 (3), ISSN2249-7315.

[8] Taranjit Kaur Raol Ms. Shiva Malik2(2012) compared Job Satisfaction of Nurses employed in Government and Private Hospitals. a quarterly published Journal of Applied Management \& Computer Science - ISSN No (0976 - 0458) Volume 1 - January 2012. 